\title{
A VIDA COMO UM BEM COMUM
}

Atualmente, para quem estuda nutrição, é no mínimo intrigante folhear jornais e revistas. Por um lado, são publicados grande número de artigos sobre a pandemia da obesidade nos mais diversos países, assim como em todas as idades e classes sociais'. Por outro, semelhante número de publicações traz à luz os problemas relacionados com a crise mundial da falta de alimentos.

interesse sobre a relação entre obesidade infanto-juvenil e classe econômica - ou nível de escolaridade da família - vem permeando as pesquisas sobre prevenção em Pediatria através dos tempos. A partir da Revolução Industrial, ocorreu progressivo aumento no risco de obesidade nos indivíduos de todo o mundo, decorrente do descompasso entre genética (que selecionou os indivíduos poupadores de energia e a preferência por alimentos mais calóricos) e cultura (que disponibilizou excessiva quantidade de alimentos e determinou a aquisição de hábitos sedentários com o desenvolvimento tecnológico).

No início da pandemia, em países desenvolvidos havia mais obesos nas classes econômicas altas². Acredita-se que a partir da sensibilização para os riscos da obesidade e do modelo estético progressivamente mais esquálido, as famílias de maior renda e escolaridade - com mais acesso a todo o tipo de informação mudaram seus hábitos e a obesidade infanto-juvenil passou a ser mais prevalente em classes econômicas mais baixas, no gênero feminino e em minorias étnicas submetidas a piores condições de vida ${ }^{3}$.

mesmo processo vem acontecendo recentemente nos países em desenvolvimento, como mostra o estudo de Rômulo Araújo Fernandes e colaboradores, intitulado "Riscos para o excesso de peso entre adolescentes de diferentes classes econômicas". Ocorreu previamente a diminuição da desnutrição e o aumento da obesidade infantil - o que foi denominado transição nutricional ${ }^{4}$ - e posteriormente a migração do risco para grupos sociais com menor acesso à informação - os de menor nível de escolaridade - como mostra esse estudo.

A filosofia de consumo excessivo da civilização ocidental mesmo o consumo aparentemente inocente de alimentos - foi contaminando as mais diversas culturas e influenciando os hábitos da maioria da população mundial, inclusive em países emergentes extremamente populosos, como a China e a Índia.

$\bigcirc$ planeta, no entanto, tem limites. Ou ocorrem mudanças significativas e profundas, para que a humanidade possa viver de forma mais equilibrada, respeitando a vida como um bem comum único, ou, como previam os filmes de ficção do século passado, terá que encontrar um novo mundo, inexplorado, para sobreviver. $\bigcirc$ mais preocupante, entretanto, é que, por toda a História do homem, sempre foi muito mais fácil - e freqüente - procurar soluções heróicas e longínquas do que tentar encontrar a solução dentro de si mesmo.

Referências

Isabela Giuliano

I. Kumanyika SK. Global calorie counting: a fitting exercise for obese societies. Annu Rev Public Health. 2008;29:297-302.

2. Zack PM, Harlan WR, Leaverton PE, Cornoni-Huntley J. A longitudinal study of body fatness in childhood and adolescence. I Pediatr. 1979;95(I): 126-30.

3.Bhargava A, Jolliffe D, Howard LL. Socio-economic, behavioural and environmental factors predicted body weights and household food insecurity scores in the Early Childhood Longitudinal Study-Kindergarten. Br J Nutr. 2008; I-7. [Epub ahead of print]

4. Monteiro CA, Mondini L, de Souza AL, Popkin BM. The nutrition transition in Brazil. Eur J Clin Nutr. 1995;49(2): 105-13.

5. Fernandes RA, Casonatto J, Christofaro DGD, Ronque ERV, Oliveira AR, Freitas Júnior IF. Riscos para o excesso de peso entre adolescentes de diferentes classes socioeconômicas. Rev Assoc Med Bras. 2008;54(4):334-8. 